\title{
3D FIB reconstruction and characterisation of a SOFC electrode
}

\author{
S. Chupin, N. Vivet, D. Rochais \& E. Bruneton \\ CEA-Le Ripault, France
}

\begin{abstract}
SOFC (Solid Oxide Fuel Cells) appear to be a great alternative way to produce electricity from hydrogen with high efficiency and no greenhouse gas emissions. SOFC are efficient at high temperatures (around $800^{\circ} \mathrm{C}$ ) and are meant to be used for stationary applications as heat and electric co-generation devices. To understand how gases, electricity and heat flow through these media and to improve their efficiency, it is critical to know the actual microstructure of these electrodes. The studied electrodes are Ni-YSZ cermets in which characteristic element sizes are around $1 \mathrm{~m}$. The $3 \mathrm{D}$ microstructure has been reconstructed using FIB (Focused Ion Beam) tomography. This technique has been used on several samples (different Ni-YSZ proportions) and gives representative 3D volumes of around $10 \times 10 \times 10 \mu \mathrm{m}$ with a $10 \mathrm{~nm}$ resolution. Theses $3 \mathrm{D}$ volumes are then analysed to extract some important structural parameters such as volumetric proportions, active surfaces, connectivity of each components and "three phase boundaries" (TPB). Then, the 3D reconstructed volumes have been used to determine homogeneous media equivalent properties such as thermal, ionic and electric conductivities. These homogeneous equivalent properties are estimated using a hot guarded plate simulation that takes into account each component properties and the 3D structure.
\end{abstract}

Keywords: SOFC, FIB, tomography, thermal conductivity.

\section{Introduction}

Solid oxide fuel cell (SOFC) based-technology is one of the most promising energy conversion systems due to its high efficiency and fuel flexibility [1]. The materials involved in their constitution have become increasingly sophisticated, both in composition and microstructure. One of the most common anode 
materials for SOFC is a porous Ni-YSZ cermet. The most important requirements for the anode are catalytic activity, stability, ionic conductivity, compatibility and porosity. For most of these conditions some experimental studies can be investigated to estimate the corresponding parameters. Recently, $3 \mathrm{D}$ reconstructions of SOFC electrodes have been performed by X-ray computed tomography (XCT) [2, 3] and mainly by focused ion beam - scanning electron microscopy (FIB-SEM) [4-7]. FIB tomography principle consists in ablating a structure physically by FIB slicing $\left(\mathrm{Ga}^{+}\right.$ions) followed by a digital reconstruction since SEM images are collected after each ablation step. The obtained images are then aligned and superimposed in order to generate the volume [8].

In the present study, the optimization approach to obtain a high quality $3 \mathrm{D}$ reconstruction of a Ni-YSZ anode using FIB-SEM is described first. Then, from these $3 \mathrm{D}$ data, various microstructural parameters, and interfacial parameters are quantified. Moreover, by solving the diffusive transport equation on the analysed volume the effective thermal, electrical and ionic conductivities of the sample have been estimated.

\section{Experimental}

\subsection{Preparation of the anodic cermet}

The deposition of the analysed NiO-8YSZ anode has been performed by screenprinting onto circular 8mol.\% yttria doped-zirconia (8YSZ) supports using ink with optimized composition and viscosity. The anode is a three layers coating on the electrolyte substrate. NiO from J.T. Baker (USA) and 8YSZ from Tosoh (Japan) have been used as raw materials to prepare the NiO-8YSZ cermet at different $\mathrm{Ni}$ volume ratio. The preparation has been done to expect the $8 \mathrm{YSZ} / \mathrm{Ni}$ volume ratio to be $60 / 40$.

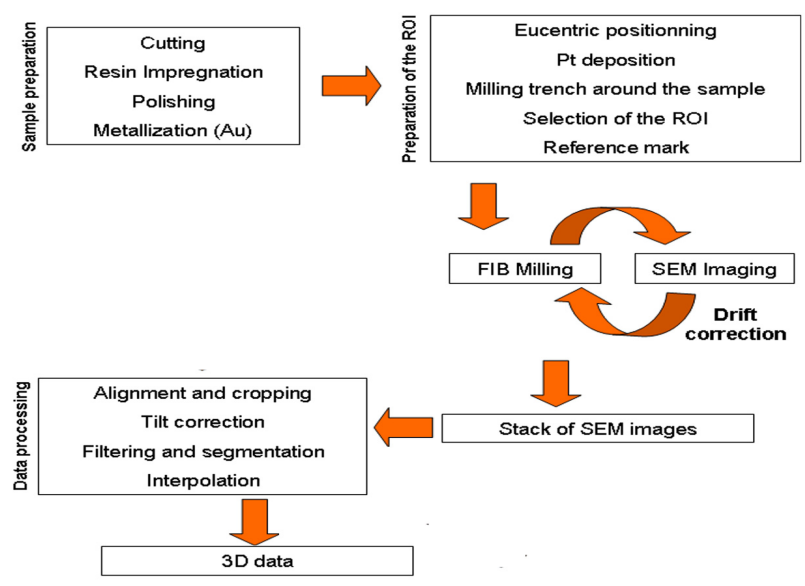

Figure 1: Schematic representation of the experimental method used to obtain the $3 \mathrm{D}$ reconstruction of the SOFC anode from FIB tomography. 


\subsection{FIB procedure}

The image set has been collected with a FEI dual-beam Strata 400-S FIB system. The procedure to obtain the $3 \mathrm{D}$ data from the initial sample is schematically presented in Figure 1.

\subsubsection{Preparation of the sample and of the region Of interest (ROI)}

In order to easily distinguish the pores during SEM observation and to avoid mistakes due to the depth of field in the SEM images, the sample has been infiltrated with an epoxy resin under vacuum. To protect the sample from accidental ion milling and erosion, a representative cross sectional area of the sample has been located by electron imaging and coated with a Pt protective layer of 2-3 $\mu \mathrm{m}$ (Figure 2) using an in-situ metallorganic ion source. Above all, $\mathrm{Pt}$ deposition associated with sample infiltration and surface polishing were necessary to avoid, or at least strongly reduce, a common artefact so-called "waterfalling" or "curtaining" effect. The FIB has been used to mill wide and deep trenches around the ROI with a maximal aperture current of 21nA, constituting a "U-shaped trench" [9]. A quite high dimension free space around the ROI is essential to prevent re-deposition of the sputtered material during the sectional milling process. If the space around the ROI is too small, images with high concentration of artefact features or uneven brightness are obtained.

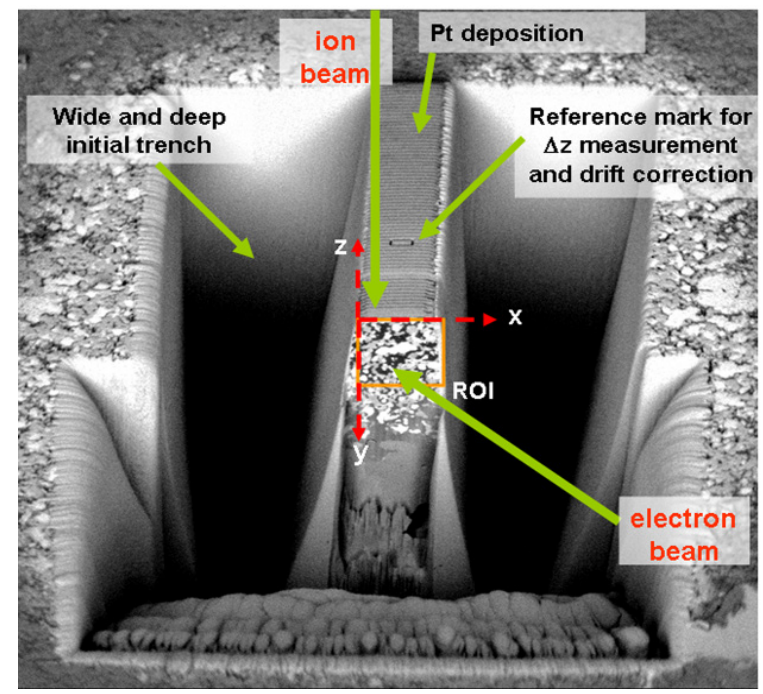

Figure 2: SEM image of the sample before the "milling and imaging" procedure. The stage tilt is kept constant at $52^{\circ}$ from the electron beam while the sample surface ( $\mathrm{xz}$ plane) is perpendicular to the ion beam (y direction). The region of interest (ROI) is displayed in the orange rectangle. The sample is sliced in the $\mathrm{z}$ direction. The small rectangle on the Pt deposition (reference mark) is used to measure the interslice $(\Delta z)$ and correct from drifting effects. 


\subsubsection{Milling and imaging process}

Since the "milling and imaging" procedure is very time consuming, uncorrected drift of electron beam, stage and sample can greatly affect the interslice real value. For this reason a correction procedure has been used [10]. The SEM and FIB operating conditions for the sequential ion milling and electron imaging have been optimized. The FIB milling has been performed with an ion-beam current of $460 \mathrm{pA}$ at $30 \mathrm{kV}$. For SEM imaging, a magnification of $12 \mathrm{kX}$ and a Through the Lens Detector (TLD) operating in BSE mode with low scan rate have been used. As the difference between the backscatter coefficients of $\mathrm{Ni}$ and $8 \mathrm{YSZ}$ are maximum for accelerating voltage smaller than $1 \mathrm{kV}$, a $0.5 \mathrm{kV}$ accelerating voltage has given an optimal contrast between Ni (bright), 8YSZ (grey) and pores (dark) (Figure 3(a)). In this case, 115 images have been recorded using a manual procedure along the sample thickness (Figure 3(a)).

\subsubsection{Data processing}

Data processing includes the following steps: i) alignment of the consecutives slices, ii) correction of the dimensions taking into account the tilt of the electron beam, iii) thresholding of the grey levels and labelling of phases, iv) resampling of the data to obtain cubic voxels and v) 3D image generation. Most of the processing steps have been performed using the AVIZO 6.2 software [11].

(a)

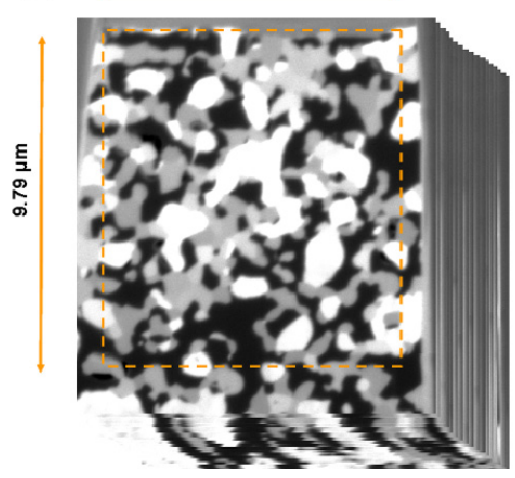

(b)

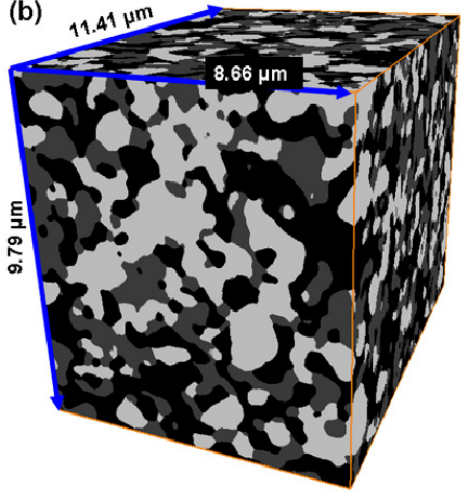

Figure 3: Images of:(a) one of the original 115 serial-sections collected with a BSE detector, so that Ni appears brighter than $8 \mathrm{YSZ}$ and that the impregnated pores appear dark, (b) final 3D image after alignment, delineate, cropping and adjustment of voxel size operations showing Ni (bright), 8YSZ (grey) and pore (dark) phases.

The absolute dimensions in the $\mathrm{x}$ direction are obtained from a calibrated SEM magnification. Because of oblique SEM imaging at an angle of $52^{\circ}$, distances in the y direction have been corrected. The 3D image dimensions is finally $8.66 \times 9.79 \times 11.41 \mu \mathrm{m}^{3}$ (volume $=967.36 \mu \mathrm{m}^{3}$ corresponding to about 1 billion voxels). 


\section{Quantification results and discussion}

First, volume fractions of each phase and their corresponding connectivity across the analysed volume have been determined. The interfacial planes surface area between two phases and the three phase boundaries lines length have been evaluated. Then, effective thermal, electronic and ionic conductivities have been estimated by solving numerically the diffusive transport equation. The most part of this quantitative analysis has been performed with home made $\mathrm{C}$ programs on a personal computer [dual CPU Intel ${ }^{\circledR}$ Xeon ${ }^{\circledR}$ E5 540 @ 2.83GHz, 32 GB RAM].

\subsection{Volume fraction}

The volume fractions calculated from 3D data have given the following results: $41 \%$ for pores, $33 \%$ for $8 \mathrm{YSZ}$ and $26 \%$ for $\mathrm{Ni}$. The solid volume fractions have been estimated to $44 \% \mathrm{Ni}$ and $56 \% 8 \mathrm{YSZ}$ in the studied anode, which are in good agreement with the expected values (40 vol.\% Ni / 60 vol.\% 8YSZ). This result provides evidence of the good representativity of the analysed volume.

\subsection{Volumetric connectivity}

In order to check the connectivity of each phase, a home made program based on a Hoshen-Kopelman algorithm has been used [12]. The voxels linked together by a face form a cluster [13]. When two voxels are only linked by a vertex or an edge, they are not considered to be connected. Finally, if a cluster is connected to the six boundary faces of the studied volume it is defined as "percolated" (Figure 4).

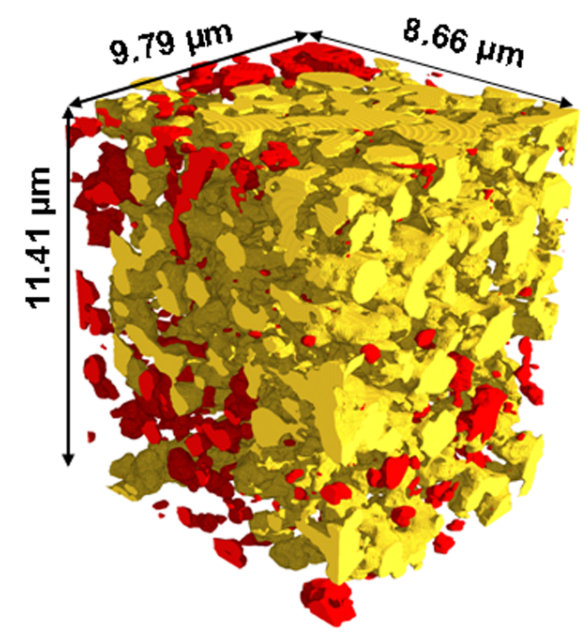

Figure 4: Ni clusters representation showing that the main part (87.4\%) of the Ni phase is percolated, i.e. in contact with the six boundary faces of the volume (in yellow). 
This analysis reveals that the three phases are mainly constituted of a very large "percolated" cluster which represents $99.8 \%, 99.1 \%$ and $87.4 \%$ of pore, 8 YSZ and Ni total volume respectively. This high percolation of all the three phases suggests good transport ability for gases in the pores, as well as for charge carrier in the solid phases.

\subsection{Interface properties}

Electrochemical and catalytic activities of an electrode are generally described by only one parameter: the $\mathrm{TPB}_{\mathrm{L}}$ which is correlated to the number of regions where the electrochemical reactions is able to take place. However not all of them may be active due to non-contiguous regions (isolated cluster). So, the specific surface and interface areas have been calculated only inside the percolated volumes.

In the pie diagram of Figure 5, the specific interface areas are indicated. Thus, about $50 \%$ of the total nickel surface is exposed to the porous phase and can be used for surface catalytic reactions with the fuel.

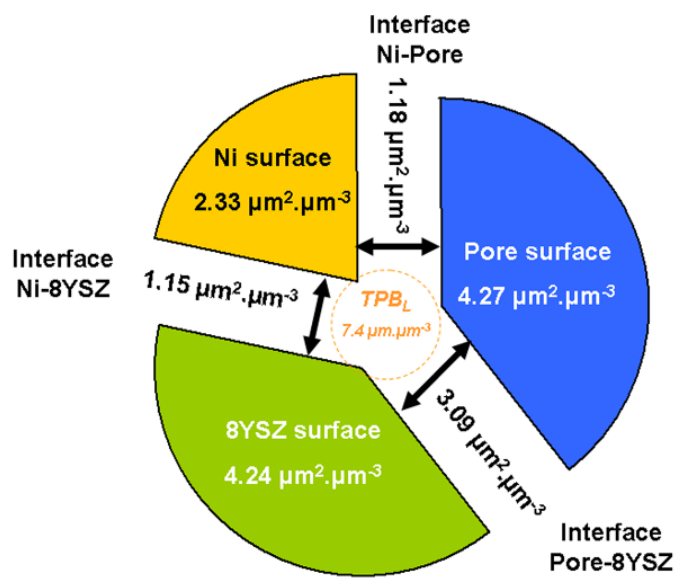

Figure 5: Pie diagram representing the specific surface areas of pores, 8 YSZ and $\mathrm{Ni}$ and the specific interface areas between the three neighbouring phases (surface and interface are normalized by volume sample). The active $\mathrm{TPB}_{\mathrm{L}}$ is $7.4 \mu \mathrm{m} . \mu \mathrm{m}^{-3}$.

The TPB are the regions where the three phases (pores, 8YSZ, Ni) meet each other. The TPB analysis procedure has been apply first to the initial volume and yields to a TPB density of $11.2 \mu \mathrm{m} . \mu \mathrm{m}^{-3}$. The "activity" of a TPB is subject to numerous definitions in the literature. The major part of the authors defined a TPB as "active", if it lies three percolated phases (pore, Ni, 8YSZ) [4, 7]. The "active" $\mathrm{TPB}_{\mathrm{L}}$ has been calculated and equal to $7.4 \mu \mathrm{m} \cdot \mu \mathrm{m}^{-3}$. This value is relatively high compared to those reported in the literature. This suggests a high electrochemical performance for the studied electrode. 


\subsection{Effective conductivities calculations}

\subsubsection{Effective diffusion coefficient calculation}

In the absence of external sources and in the case of the steady state condition, the distribution of $\theta$ (for all conduction or diffusion phenomena) in the material is governed by the diffusive transport equation [14]:

$$
\vec{\nabla} \cdot(-\mathrm{D} \vec{\nabla} \theta)=0
$$

$\mathrm{D}$ is defined as the diffusion coefficient in the material. Each voxel is considered uniform with a given diffusion coefficient depending of its phase $\left(D_{\text {voxel. }}\right.$ Table 1). This equation is solved using an implicit finite difference method based on a conjugate gradient algorithm [14]. Different Dirichlet boundary conditions are fixed on two opposite faces $\left(\theta=\theta_{1}\right.$ on one face and $\theta=\theta_{2}$ on the opposite). Null Neumann boundary conditions are imposed on the other faces. Once the $\theta$ distribution within the volume is obtained (Figure 6), the average flux $(\Phi)$ over a cross section of surface area $\mathrm{S}$ can be calculated:

$$
\Phi=\iint_{\mathrm{S}}-\mathrm{D}_{\text {voxel }} \vec{\nabla} \theta \cdot \overrightarrow{\mathrm{n}} \mathrm{dS}
$$

Table 1: Thermal, ionic and electronic conductivities at $1123 \mathrm{~K}$ of pores, $8 \mathrm{YSZ}$ and Ni data [17-21].

\begin{tabular}{cccc}
\hline & Pores & $8 \mathrm{YSZ}$ & $\mathrm{Ni}$ \\
\hline$\lambda\left(\mathrm{W} \cdot \mathrm{m}^{-1} \cdot \mathrm{K}^{-1}\right)$ & $\left(\mathrm{H}_{2}\right) 0.48$ & 2 & 50 \\
\hline$\sigma$ ionic $\left(10^{-3} \mathrm{~S} \cdot \mathrm{cm}^{-1}\right)$ & 0 & 14 & $10^{-5}$ \\
\hline$\sigma$ electronic $\left({\left.\mathrm{S} . \mathrm{cm}^{-1}\right)}^{-1}\right.$ & 0 & $10^{-6}$ & $10^{4}$ \\
\hline
\end{tabular}

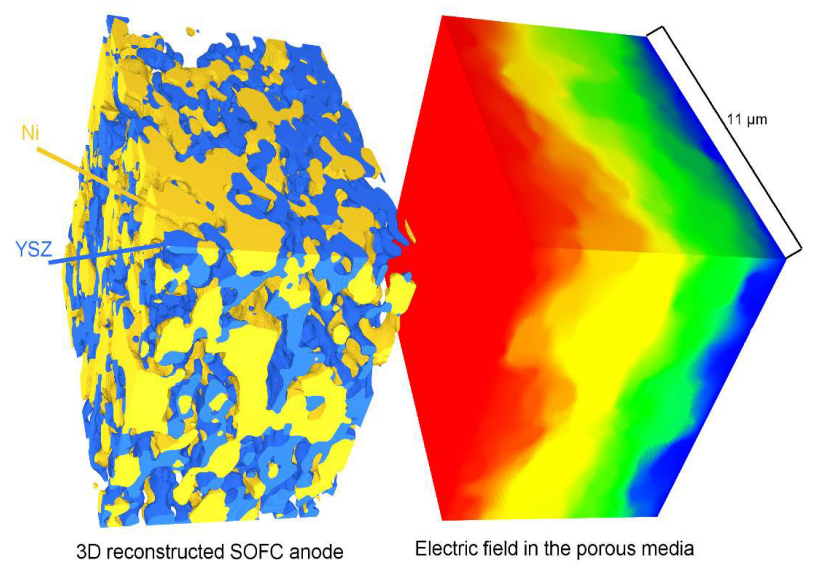

Figure 6: Reconstructed 8YSZ-Ni SOFC Anode and the electric field resulting of a $1 \mathrm{~V}$ potential difference between two opposite faces. 
For the equivalent homogeneous material, the average conduction flux $\Phi$ can be written [14]:

$$
\Phi=D_{\text {eff }} S \frac{\left(\theta_{1}-\theta_{2}\right)}{x_{i \max }}
$$

The combination of eqns (2) and (3) leads to estimate $\mathrm{D}_{\text {eff }}$ as:

$$
D_{\text {eff }}=\frac{x_{i \max }}{S\left(\theta_{1}-\theta_{2}\right)} \iint_{S}\left(-D_{\text {voxel }} \frac{\partial \theta}{\partial x_{i}}\right) d S
$$

At $1123 \mathrm{~K}$ and under one atmosphere the mean free path of $\mathrm{H}_{2}$ is around $900 \mathrm{~nm}$, and is bigger than our voxel size [15]. Then the concentration cannot be considered uniform in a voxel and the bulk diffusion assumption is not valid anymore. In the case of electron, ion and heat transport the corresponding mean free path are smaller than $100 \mathrm{~nm}$. So, only heat, ion and electron diffusive transport have been calculated in this work.

The results are given in Table 2 where the different values of $\mathrm{D}_{\text {eff }}$ are reported under the form of thermal, electronic and ionic effective conductivities. The effective thermal conductivity appears quite isotropic with a slighter lower value in the $\mathrm{z}$ direction, close to $4 \mathrm{~W} \cdot \mathrm{m}^{-1} \cdot \mathrm{K}^{-1}$. This value has the same order than those generally reported for SOFC anodes [16].

Table 2: $\quad$ Thermal, electronic, ionic effective conductivities in the $\mathrm{x}, \mathrm{y}$ and $\mathrm{z}$ directions from the calculation of $\mathrm{D}_{\text {eff }}$ at $\mathrm{T}=1123 \mathrm{~K}$.

\begin{tabular}{cccc}
\hline & $\mathrm{x}$ & $\mathrm{y}$ & $\mathrm{z}$ \\
\hline$\lambda\left(\mathrm{W} \cdot \mathrm{m}^{-1} \cdot \mathrm{K}^{-1}\right)$ & 4.23 & 4.54 & 3.27 \\
\hline$\sigma$ ionic $\left(10^{-3} \mathrm{~S} . \mathrm{cm}^{-1}\right)$ & 1.43 & 1.19 & 1.03 \\
\hline$\sigma$ electronic $\left(\mathrm{S} . \mathrm{cm}^{-1}\right)$ & 281 & 252 & 66 \\
\hline
\end{tabular}

The effective electronic conductivity appears anisotropic: the $\sigma_{\text {electronic }}$ value in the $\mathrm{z}$ direction is smaller than the ones in the $\mathrm{x}$ and $\mathrm{y}$ direction. The evolution of the $\mathrm{Ni}$ concentration along each axes has shown that the Ni proportion along $\mathrm{z}$ in more important than along the other axes. It creates a stricture effect that decreases the effective conductivity. Experimental four-point electrical measurements performed at $1123 \mathrm{~K}$ on the anode surface lead to a value of the same range: $81 \mathrm{~S} . \mathrm{cm}^{-1}$.

Ionic conductivity in the studied anode is quite isotropic and close to $10^{-3}$. As a value of $1.410^{-2}$ had been used for the calculation, the microstructural effect for the loss of conductivity is closed to a factor 10 .

\section{Conclusion}

This work has focused on the 3D analysis of the microstructure in a Ni-8YSZ SOFC anode reconstructed by FIB tomography. Sample preparation, milling and 
imaging conditions and data processing have been optimized to obtain a high quality representative 3D microstructure having the following dimension of $8.66 \times 9.79 \times 11.41 \mu \mathrm{m}^{3}$. Home made programs have led to the calculation of some microstructural parameters such as volume fraction, connectivity, specific surface and interface areas and TPB length including the proportion of active and non active ones. These calculations have shown that for an anode with an initial $8 \mathrm{YSZ} / \mathrm{NiO}$ volume ration of $60 / 40$ leading after reduction to volume relative amounts $41 \%$ of pores, $33 \%$ of $8 \mathrm{YSZ}$ and $26 \%$ of Ni, all the phases were highly percolated. The active TPB length has been estimated as $7.4 \mu \mathrm{m} / \mu \mathrm{m}^{3}$ which comparing to the literature results corresponds to an effective anode. By solving the diffusive transport equation with finite difference calculations, the effective thermal, electronic and ionic conductivities could be determined.

\section{References}

[1] S. Singhal, K. Kendall, High-Temperature Solid Oxide Fuel Cells: Fundamentals, Design and Applications, Elsevier Advanced Technology, Oxford, UK, 2003.

[2] P.R. Shearing, J. Gelb, N.P. Brandon, X-ray nano computerised tomography of SOFC electrodes using a focused ion beam samplepreparation technique, J. of the Europ. Ceram. Soc., 30 (2010) 1809-1814.

[3] K.N. Grew, A.A. Peracchio, W.K.S. Chiu, Characterization and analysis methods for the examination of the heterogeneous solid oxide fuel cell electrode microstructure, Part 2 : Quantitative measurement of the microstructure and contributions to transport losses, J. Power Sources, 195 (24) (2010) 7943-7958.

[4] J.R. Wilson, W. Kobsiriphat, R. Mendoza, H.-Y. Chen, J.M. Hiller, D.J. Miller, K. Thornton, P.W. Voorhees, S.B. Alder, S.A. Barnett, Threedimensional reconstruction of a solid-oxide fuel-cell anode, Nature Materials, 5 (2006) 541-544.

[5] S.A.Barnett, J.R. Wilson, W. Kobsiriphat, H.-Y. Chen, R. Mendoza, J.M. Hiller, D.J. Miller, K. Thornton, P.W. Voorhees, S.B. Alder, Three dimensional analysis of solid oxide fuel cells using Focused ion beamScanning electron microscopy, Microsc. Microanal., 13 (2007) 596-597.

[6] D. Gostovic, J.R. Smith, D.P. Kundinger, K.S. Jones, E.D. Washman, Three-dimensional reconstruction of porous LSCF cathodes, Electrochem. Solid-State Lett., 10 (12) (2007) B214-B217.

[7] L. Holzer, B. Munch, B. Iwanschitz, M. Cantoni, T. Hocker, Th. Graule, Quantitative relationships between composition, particle size, triple phase boundary length and surface area in Ni-cermet for Solid Oxide Fuel Cells, J. Power Sources, doi : 10.1016/j.jpowsour.2010.08.006.

[8] L. Holzer, B. Muench, M. Wegmann, P.H. Gasser, R.J. Flatt, FIB-nanotomography of particulate systems - Part 1 : Particle shape and topology of interfaces, J. Am. Ceram. Soc., 89 (2006) 2577-2585.

[9] J.R Wilson, J.S Cronin, S.A. Barnett, Linking the microstructure, performance, and durability of Ni-Yttria-Stabilized Zirconia solid oxide 
fuel cell anodes using three dimensional focused ion beam - Scanning electron microscopy imaging, Scripta Materialia, doi 10.1016/j.scriptamat.2010.09.025.

[10] B. Ruger, J. Joos, A. Weber, T. Carraro, E. Ivers-Tiffée, 3D-modeling and performance evaluation of mixed conducting (MIEC) cathodes, ECS Transactions, 25 (2) (2009) 1211-1220.

[11] <http://www.vsg3d.com>

[12] J. Hoshen, R. Kopelman, Percolation and cluster distribution. I. Cluster multiple labelling technique and critical concentration algorithm, Phys. Rev. B., 1 (14) (1976) 3438-3445.

[13] Y. Nakashima, S. Kamiya, Mathematica programs for the analysis of three-dimensional pore connectivity and anisotropic tortuosity of porous rocks using X-ray computed tomography image data, J. Nucl. Sci. Technol., 44 (9) (2007) 1233-1247.

[14] D. Rochais, G. Le Meur, V. Basini, G. Domingues, Microscopic thermal characterization of HTR particle layers, Nucl. Eng. And Design, 238 (2008) 3047-3059.

[15] T.G. Sherwood, R.L Pigford, C.R. Wilke, Mass transfer, In:Clark, B.J. Maisel, J.W. (Eds.) McGraw-Hill Inc., New York, pp. 39-43, 1975.

[16] S. Kakaç, A. Pramuanjaroenkij, X.Y. Zhou, A review of numerical modelling of solid oxide fuel cells, J. Hydrogen Energy, 32 (2007) 761-786.

[17] D.R. Lide, Handbook of Chemistry and Physics, Thermal Conductivity of gases, chap. 6, p 206, 89 th. ed., Taylor and Francis, Boca Raton (2008).

[18] K.W. Schlichting, N.P. Padture, P.G. Klemens, Thermal conductivity of dense and porous yttria-stabilized zirconia, J. Mat. Sci., 36 (2001) 3003-3010.

[19] Y.S. Touloukian, R.W. Powell, C.Y.Ho, P.G. Klemens, Thermophysical Properties of matter, vol. 1, Thermal conductivity, metallic elements and alloys., IFI/Plenum, New-York-Washington, 1970.

[20] R. Landauer, The electrical resistance of binary metallic mixtures, J. Appl. Phys., 23 (1952) 779-784.

[21] Z. Wu, M. Liu, Modelling of ambipolar transport properties of composite mixed ionic-electronic conductors, Solid State Ionics, 93 (1997) 65-84. 